\title{
Using a self-care management tool to improve self-care and quality of life in patients with congestive heart failure
}

\author{
Azza Fathi Ibrahim*1, Faiza Mohammed Tawfik², Mohammad Othman Abudari ${ }^{3}$ \\ ${ }^{1}$ Nursing Education Department, Faculty of Nursing, Alexandria University, Egypt \\ ${ }^{2}$ Faculty of Nursing, Medical Surgical Nursing Department, Alexandria University, Egypt \\ ${ }^{3}$ Community Health Nursing Department, Faculty of Nursing, Batterjee Medical College, Saudi Arabia
}

Received: February 23, 2016

Accepted: April 10, 2016

Online Published: April 27, 2016

DOI: $10.5430 /$ cns.v4n $3 p 1$

URL: http://dx.doi.org/10.5430/cns.v4n3p1

\begin{abstract}
Self-management is a primary goal for multiple chronic diseases and particularly for Congestive Heart Failure (CHF). Currently, treatment for $\mathrm{CHF}$ emphasizes relieving symptoms through teaching patients how to better care for themselves. Patients who take an active role in self-care are more independent; feel more able to manage their disease and experience better psychological outcomes. However, the research focused on self care-management intervention in heart failure patients in Egypt is very inadequate. Thus, this study aims to first explore the self-care management learning needs among patients with CHF, then secondly assess the effects of a self-care-management tool on self-care adequacy and quality of life (QOL) among this group of patients and thirdly identify patient opinions regarding the instructional developed tool. The research design encompasses the two designs of descriptive and quasi-experimental pretest-posttest study. A convenient sample of 256 patients with congestive heart disease was employed for the survey group in the assessment phase of the study. From this sample, $30 \%$ were then randomly assigned to use the developed instructional tool as the experimental group. Two tools were used for data collection. The first was the Heart Failure Self-Care Management Questionnaire (HFSCMQ) which included two parts: the Self-Care Heart Failure Index which was developed by Riegel et al., in 2009, and the Minnesota Living with Heart Failure Questionnaire (MLHFQ) that was developed by Rector T, in 1986. The second tool was a patient feedback opinionnaire which was developed by the researchers to determine patient's feedback after using the developed tool. Results for the survey group revealed observed inadequate self-care management as perceived by patients with CHF involving self-care maintenance, self-care management and self-care confidence elements, as well as poor QOL detection. Results for the experimental group showed that the CHF patient's perceptions about self-care management with its components were improved before and after use of the developed instructional tool in the second and third assessments. As well, the QOL was slightly improved as perceived by them. This proves that the self-care management tool may be effective as a self-learning reference among Egyptian CHF patients. In conclusion, instructional health education materials, particularly for patients with chronic illnesses such as CHF, are essential nursing interventions to improve patient self-care management literacy and the QOL. Furthermore, the planning, developing, and implementing of different health instructional materials for patient teaching has become a necessary scheme for nurses to improve their practice in exploring innovative roles in the health education field and activate these roles in different health specialties.
\end{abstract}

Key Words: Congestive heart failure, Patients, Self care, Management tool, Quality of life

*Correspondence: Azza Fathi Ibrahim; Email: azza_fathy2008@yahoo.com; Address: Nursing Education Department, Faculty of Nursing, Alexandria University, Egypt. 


\section{INTRODUCTION}

Assisting patients and families in dealing with chronic conditions is an essential issue nowadays and is receiving high attention in health care fields. Many patients with chronic diseases have limited literacy and lack of awareness about their self-care. Almost all of them cannot contribute to the decision making process about their health management Therefore, they need serious help regarding teaching them how to deal with their illness independently in the absence of health professionals. Self-care is a process of maintaining health through treatment adherence and symptom monitoring. When signs and symptoms occur, decision making regarding self-care management is required. It is, of course, positively influenced by self-confidence and efficacy in one's abilities. ${ }^{[1-3]}$ Awareness of treatment adherence and literacy of disease signs and symptoms are the keys and basic elements of self-care management which should be a dynamic, deliberate decision-making process assumed as a self-governing reaction to illness complaints. Self-care management is a crucial process that helps to control an unsteady balance between relative health and disease reactions. A self-care management process entails symptom identification, symptom evaluation, treatment implementation and treatment evaluation. ${ }^{[2,4,5]}$ Self-care reflects individual responsibility for health behaviors and the development of activities required to manage and monitor health conditions.

Self-care in chronic diseases concerns the preservation of physical and psychological well-being, diminishment of the incidence of morbidity and mortality, reduction of healthcare cost, increase in patient satisfaction and the improvement of life quality. These are all benefits of self-care management in people with chronic diseases such as $\mathrm{CHF}^{[3,5]}$

Congestive Heart Failure (CHF) is a widespread and persistent condition in Egypt which has a big cost and disability burden on patients. In addition, it is a critical medical condition encountered by health care professionals. CHF is considered an epidemic health problem and its incidence and prevalence has increased worldwide wherein $18 \%$ of evidenced deaths are attributed to heart failure. Furthermore, physicians frequently attribute heart failure to be the cause of death when the reason is unknown. ${ }^{[6-8]} \mathrm{CHF}$ is a dangerous clinical syndrome resulting from an incapability of the heart to maintain sufficient blood circulation. Many congestive diseases result in heart failure (e.g., myocardial infarction and hypertension) and more than 400,000 new cases of congestive heart failure are diagnosed annually. ${ }^{[9,10]}$ While there have been advances in medical treatment and symptom management for CHF, patients still experience poor quality of life (QOL) overall.
The signs and symptoms of heart failure include shortness of breath, fatigue, peripheral swelling, difficulty sleeping in a supine position, coughing, inability to perform normal activities of daily living, and a sudden weight gain due to fluid retention. Dizziness, lightheadedness, and palpitations are common worrisome symptoms that suggest dysrhythmias or hypotension. A sudden, unintentional weight loss may be an indication of cardiac cachexia. If patients with heart failure were aware of its signs, symptoms, management, monitoring of symptoms regularly with appropriate drugs, and how to evaluate the effectiveness of those drug actions, they would maintain a stable state of the disease and reach a higher QOL. Therefore, self-care management is a fundamental element of successful treatment for patients with $\mathrm{CHF}^{[7,10,11]}$

Effective self-management is essential for CHF patients as it may prevent disease exacerbations and hospital readmissions. Consequently, patients need to improve their abilities to manage their chronic condition on a day-to-day basis. ${ }^{[12,13]}$ Suitable self-care management of CHF is strictly linked with admirable health outcomes. Thus, patients should follow self- care management compliance instructions for numerous management strategies such as diet adjustment, fitting physical activity, fluid intake and output regulation, and arrangement of a multifaceted medication regimen. Patients who can successfully self-manage their symptoms will have limited suffering and a better life style with this chronic disease. $^{[2,14-16]}$

There are several aids to help the nurse as a health educator in assessing, modifying, persuading teaching, guiding, reinforcing, and changing patient behaviors. One is a self-care management tool which is an essential aid in patient health education activities in such chronic diseases. ${ }^{[17,18]}$ Health educators should establish health education self-management tools as better ways for planning, documenting, referencing and presenting more effective health messages and health information for this group of patients. By fostering self-care awareness and self-management skills through use of these tools, health care professionals can guide patients to become competent in their health care. By using specific tools to promote self-management, nurses will help patients to work out plans for themselves such as crises management and maintenance of equilibrium after the crisis. ${ }^{[15,16]}$ These tools encourage patients to observe their disease in more depth than they may have done previously. As well, it may help patients to be extra self-confident in asking for what they feel or know as well as becoming more resourceful on reasonable requests. Successful self-care management tools require a knowledgeable, engaged, and dedicated patient with supportive caregivers, family and friends, entrenched in a healthcare system that facilitates self-care management practices. ${ }^{[17,18]}$ 
Additionally, self-care management tools are educational methods that are important approaches to be used for adult patients who have continuous and intense health needs such as those with CHF. They are good references for reinforcing understanding of disease problems and acting upon this understanding. Moreover, they encourage patients in performing effective and organized self-care that consequently affects their overall health patterns. ${ }^{[17-19]}$ Nurses have the key and most important role in health teaching for supporting and persuading patients in performing self care. They act as health educators in almost all health care settings to develop patient health literacy and assist them in taking control and becoming familiar with their chronic disease. Nurses should interact with patients to identify their educational needs, provide health education intervention appropriately with fitting methodology and appraise patient health outcome. Self-care management tools are brilliant approaches in helping patients and nurses reach their goals in health concerns. The selfcare management collaboration of patients with nurses is important for illness adaptation, self-care success and QOL improvement. ${ }^{[20,21]}$

Self-care management tools present to patients in the forms of handouts and printed material. These can include diagrams, pictures and colors which are primarily intended for attracting and guiding patients to actively participate in their self-care management independently. Self-care management tools help to put the need, purpose, objectives and health messages down on paper to be understood easily by the reader in self learning. ${ }^{[21,22]}$ Therefore, a patient with $\mathrm{CHF}$ may have an intense need for these materials and particularly self-care management tools that manage their disease problems. The purpose of this methodological study is to develop, apply and evaluate self-care management tool among patients with CHF. Health care professionals would then be able to use this tool to teach and evaluate deficiencies in the self-management process and to identify specific patient education and counseling needs. As well, nurses could use this instrument to help them check and revise various patient selfcare interventions to improve patient self-care management, particularly with CHF.

As a step to improve patient health literacy and self-care practices, using self-care management tools for patients with $\mathrm{CHF}$ such as printed materials comprised of all aspects of illness care, signs, symptoms and appropriate self-care behaviors, can be extremely effective and also contribute to noticeable progress for professional nursing experiences in health education. To fulfill the study aims, the following hypotheses were developed:

Research hypotheses:
(1) Patients with CHF who are educated by a developed self-care management tool exhibit higher scores in A Self-Care of Heart Failure Index (SCHFI) than those who were not educated by such a tool.

(2) Patients with CHF who were educated by a developed self-care management tool exhibit lower scores in The Minnesota Living with Heart Failure Questionnaire (MLHFQ) than those who were not educated by such a tool.

\section{METHOD}

\subsection{Study design}

A descriptive design was used in the first part of the study in the form of a survey, and then a quasi-experimental pretestposttest study design was applied in the second.

\subsection{Sample and setting}

The study was conducted at the three medical sections of El Amerey Hospital in Alexandria, Egypt. The sample size was determined by an epidemiological information statistical program to be not less than 250 in a survey phase. A convenient sample of 256 adult patients with CHF, male and female, was used as a survey group. Then randomly, the researchers selected $30 \%$ of the survey group to be an experimental group which included 80 patients who were instructed to use the developed tool. The researcher considered matching techniques to ensure the representativeness of the experimental group. Subject inclusion criteria were: age range of 30 to 70 years old, alertness, ability to read, write and communicate, having been diagnosed of $\mathrm{CHF}$ for at least two years, freedom from any other systemic associated diseases, full dependency on El Amerey Hospital for treatment and finally have a willingness to participate in the study by signing a written consent.

\subsection{Study tools}

Two tools were used for data collection:

\subsubsection{Heart Failure Self-Care Management Question- naire (HFSCMQ)}

It included two parts:

(A) SCHFI: Self-care behavior was measured by the Chinese version of the 6.2 (SCHFIV6) which is a self-administered instrument that yields a performance rating score and has 3 subscales: selfcare maintenance (10 items), self-care management (6 items), and self-care confidence (6 items). It was developed by Riegel et al., in $2009,{ }^{[2]}$ to determine the level of self-care adequacy. This instrument uses a quantitative, ordinal numerical Likert scale for self-reporting of $\mathrm{CHF}$ self-care achievement. The numerical values range from 
0-4 and 1-4, for each item, depending on the frequency of self-care activities. Each subscale is standardized to a score of 100; for example, a self-care maintenance score mean compared to poor, 70 (16.9); good, 80 (12.2); and expert, 85 (5.0). The frequency of self-care maintenance activities ranges from $1=$ never or rarely and $4=$ always or daily. While for the self-care management scale, the frequency was represented through 6 items; the first ranging from 0 $=$ didn't recognize the symptoms at all to $4=\mathrm{I}$ recognize the symptoms very quickly. The second, third, fourth and fifth items corresponded to a range between $1=$ not likely to $4=$ very likely. The third scale is a self-care confidence (six items) that range as follows: $1=$ not confident to $4=$ extremely confident.

The reliability and validity of this instrument were proved in previous researches and its developer recommended scoring the 3 subscales individually (scores range from $0-100$ on each) instead of determining a total summary score. ${ }^{[2]}$

(B) The MLHFQ was used to measure the level of QOL. It is intended to assess the effects of CHF and treatments on patient QOL based on Rectors' work in $2005^{[1]}$ which relates clinical assessments and patient perceptions to QOL. It was developed in 1984 and is the most commonly used instrument in CHF QOL research. The questionnaire consists of 21 items in a 6-point Likert format, ranging from 0-5. It requires patients to indicate i.e., $0:$ no, 1 : very little, and 5: very much to clarify how each item in the scale affects their living as they wish, over the past four weeks. The questions reflect the four factors affecting QOL for patients with $\mathrm{CHF}$ including physical, emotional, social, and mental states. The MLHFQ score ranges from 0 to 105 , the higher the score the lower the QOL. The reliability and validity of this instrument were confirmed in previous research. ${ }^{[1]}$

In addition, socio-demographic data was attached such as age, sex, marital status, residence, length of hospitalization etc.

Both parts A and B were translated into Arabic by four experts in Arabic, English and the medical cardiology fields in order to be applicable, feasible and understandable by Egyptian patients. Both were statistically tested for reliability. The SCHFI was tested by the Cronbach Alpha Coefficient Statistical Test $>\alpha=0.76$. The MLHFQ consistently demonstrated a more satisfactory level of reliability; $>\alpha=0.80$. Content validity had been determined for both parts by a jury of experts in medical surgical, community and nursing education to ensure content and criterion related validity.

\subsubsection{Patient Feedback Assessment Sheet (PFAS)}

It was developed by the researchers after review of related literature to determine experimental group feedback and im- pressions after using the developed tool. It consisted of 12 statements in a 5-point Likert format, ranging from 1-5. It required patients to select from a range of 1: very little to 5: very much to illustrate to which extent the developed tool has a value and reflects this value in patient opinions. The scale items were about tool attractiveness, clarity, applicability etc. Positive patient feedback about the developed tool was represented above $50 \%$ whereas the mean of statements had to be above 3; while negative feedback was represented below $50 \%$. In addition, open ended questions were included about strong points, weak points and patient suggestions regarding the developed self-care management tool.

\subsection{Data collection}

The authorities of El Amerey Hospital approved the study protocol. A pilot was carried out on twenty seven patients with CHF apart from the study subjects and necessary modifications were done. Once recruited, patients were informed regarding the purpose and procedure of the study and given a written informed consent. All information was kept confidential and all data was presented as group data to preserve anonymity. Participants were informed that due to the voluntary nature of their participation, they could withdraw at any time. The survey group received and filled the Study Tool I that only included part A and B. Then, based on survey group responses and extensive literature review, a self-care management tool was developed. This process of development was carried out in four consecutive phases of survey, preparation, conduction and evaluation:

- Survey phase: Study Tool I was used with the survey group on an individual basis in the presence of the researchers to guide them and answer any perceived vague questions.

- Preparation phase: Based on a thorough review of related literature and the survey phase, a self-care management tool was prepared including objectives, contents, pictures and instructions. The tool content was revised by a jury of seven experts in medical surgical, community and nursing education fields to ensure its content validity. The jury systematically examined the instruction content to determine whether it covered a representative sample of the behavior domains to be measured. Also, they identified the degree to which evidence and theory supported the details of the tool content including pictures, knowledge and actions that should be taken by the patients. As well, the tool was used by eleven CHF patients who were separated from the study groups in order to check its feasibility. Accordingly, modifications were done.

- Conduction phase: A developed self -care management tool in the form of a handout, visual aid and refer-

ISSN 2324-7940 E-ISSN 2324-7959 
ence for self-learning was used with the experimental group only. Each patient in the experimental group was instructed in: (1) the routine care and knowledge for his/her condition that maintained stability of the disease; (2) any variation in the health condition that warned him/her to call the physician and seek medical help; (3) dangerous signs and symptoms that needed immediate medical intervention and hospitalization. Each patient restated all instructions given two times and the researchers ensured that each patient was able to use the tool as a reference if needed at home. Examples, clarifications, questions and explanations were provided during researcher-patient instruction. Each patient received two teaching sessions, one for instruction and the other for revision. Each session lasted about two hours. Follow up was strictly enforced every two days. If a patient had been discharged, he/she was followed by telephone and asked to attend follow up at the outpatient clinic.

- Evaluation phase: An experimental group was assessed by Tool I three times: (1) before using the developed tool (in the survey phase) as a baseline data collection in a 1 st assessment, (2) after the two sessions of instruction as a 2 nd assessment and (3) four weeks after the two sessions of instructions as a 3 rd assessment. The scores of the study tool before and after instructions for the experimental group in the three assessments were compared. The difference between the scores was estimated to determine the effect of using the developed tool as a self-reference for patients with CHF. Moreover, the experimental group was asked to fill Tool II after $3^{r d}$ assessment to determine their feedback and evaluation about using the developed tool.

\subsection{Data analysis}

Collected data was computerized, coded, analyzed and tabulated. Statistical Packages for the Social Sciences (SPSS) version 19.0 for Windows and Microsoft Excel Spread Sheet Package (Office 2010) were used for the results of the study. Tests for significance were used; mean and standard deviation as well as percentage, frequency, chi-square, $t$-test and $p$-values.

\section{RESUlts}

Results in the current study passed through two stages:

- Results of survey group and

- Results of the experimental group

Table 1 shows that more than half of the survey and experimental groups $(54.7 \%, 56.3 \%)$ were in their sixties age-wise, and the majority $(73.4 \%, 76.3 \%)$ of both were males. As well, more than one half of them $(52 \%, 56.2 \%)$ were married but the minority of both $(24.6 \%, 26.6 \%)$ was widowed. Approximately one half $(47.7 \%, 51.3 \%)$ of them were workers. In addition, more than one half of the survey group (51.6\%) had a preparatory or primary education level while approximately the same percent in the experimental group (51.2\%) had technical or secondary education. Moreover, exceeding half of both $(53.1 \%, 52.5 \%)$ had respiratory problems with CHF. About two thirds of the survey and experimental groups $(57.8 \%, 63.7 \%)$ were smokers. Finally, nearly all of both groups had never before used self-care management references. In general, there was no statistically significant difference noticed between the survey and experimental groups in relation to socio-demographic characteristics and level of significance $<0.05$ except in marital status and level of education; $p$-value $=.02 \& .00$.

\subsection{Results for survey group}

Tables 2-4 are presenting the results of the SCHFI through the three subscales: self-care maintenance, self-care management and self-care confidence as per the first research hypothesis.

Concerning Table 2, which clarifies self-care maintenance among the survey group, it was noticed that almost all items, excluding items No. 2 and 5, have a mean of less than 2.00 which indicates that the total score for self-care maintenance among the survey group is below 50\%. As regards items 2 and 5 , it is clear that these items have a mean slightly above 2.00 which indicates inadequate self-care maintenance perceptions in relation to checking ankles for swelling and keeping doctor or nurse appointments. According to Riegel et al., 2009, if self-care at any subscale in SCHFI is below $70 \%$, this denotes inadequate self care. Total means $=1.5$ for all self-care maintenance items which represents inadequate self-care maintenance among survey group in general.

In Table 3, regarding self-care management, in the second subscale of the SCHFI, almost all of the survey group $(91.4 \%)$ had trouble breathing or ankle swelling in the past month. This is the only group who completed answering the scale items to investigate their self-care management for perceived symptoms. Their responses were with a mean of less than 2.00 for almost all scale items for symptom recognition, treatment implementation and treatment evaluation. This denotes inadequate self-care management, especially in item 6 which has the lowest mean $(0.77)$ regarding assurance that the remedy helped. The total means $=1.3$ for all self-care management items representing self-care inadequacy among the survey group in general. 
Table 1. Socio-demographic characteristics of both survey and experimental groups

\begin{tabular}{|c|c|c|c|c|c|c|}
\hline \multirow{2}{*}{\multicolumn{2}{|c|}{ Socio-demographic characteristics }} & \multicolumn{2}{|c|}{ Survey group $(\mathrm{N}=256)$} & \multicolumn{2}{|c|}{ Experimental group $(\mathrm{N}=\mathbf{8 0})$} & \multirow{2}{*}{$\begin{array}{l}\text { Test of } \\
\text { significant }\left(\chi^{2}\right)\end{array}$} \\
\hline & & \multirow{2}{*}{$\begin{array}{l}\text { No. } \\
24\end{array}$} & \multirow{2}{*}{$\begin{array}{l}\% \\
9.3\end{array}$} & \multirow{2}{*}{$\begin{array}{l}\text { No. } \\
2\end{array}$} & \multirow{2}{*}{$\begin{array}{l}\% \\
2.5\end{array}$} & \\
\hline \multirow{4}{*}{ Age } & $30-40$ & & & & & \multirow{4}{*}{$\begin{array}{l}\chi^{2}=4.25 \\
p \text {-value }=.24\end{array}$} \\
\hline & $40-50$ & 52 & 20.4 & 18 & 22.5 & \\
\hline & $50-60$ & 140 & 54.7 & 45 & 56.3 & \\
\hline & $60-70$ & 40 & 15.6 & 15 & 18.7 & \\
\hline \multirow{2}{*}{ Sex } & Male & 188 & 73.4 & 61 & 76.3 & \multirow{2}{*}{$\begin{array}{l}\chi^{2}=0.25 \\
p \text {-value }=.62\end{array}$} \\
\hline & Female & 68 & 26.6 & 19 & 23.7 & \\
\hline \multirow{4}{*}{ Marital status } & Single & 44 & 17.2 & 41 & 16 & \multirow{4}{*}{$\begin{array}{l}\chi^{2}=9.63 \\
p \text {-value }=.02^{*}\end{array}$} \\
\hline & Married & 133 & 52 & 144 & 56.2 & \\
\hline & Divorce & 16 & 6.2 & 3 & 1.2 & \\
\hline & Widowed & 63 & 24.6 & 68 & 26.6 & \\
\hline \multirow{5}{*}{ Occupation } & Worker & 122 & 47.7 & 41 & 51.3 & \multirow{5}{*}{$\begin{array}{l}\chi^{2}=2.58 \\
p \text {-value }=.63\end{array}$} \\
\hline & Employee & 46 & 17.9 & 13 & 16.2 & \\
\hline & Farmer & 30 & 11.7 & 13 & 16.3 & \\
\hline & Retired & 35 & 13.7 & 7 & 8.7 & \\
\hline & Unemployed & 23 & 9.0 & 6 & 7.5 & \\
\hline \multirow{4}{*}{ Level of Education } & $\operatorname{High}^{€}$ & 32 & 12.5 & 19 & 23.8 & \multirow{4}{*}{$\begin{array}{l}\chi^{2}=45.42 \\
p \text {-value }=.00^{* *}\end{array}$} \\
\hline & Moderate $^{\S}$ & 56 & 21.9 & 41 & 51.2 & \\
\hline & Lower than moderate $^{\dagger}$ & 132 & 51.6 & 10 & 12.5 & \\
\hline & $\begin{array}{l}\text { Low literacy } \\
\text { (in reading \& writing) }\end{array}$ & 36 & 14 & 10 & 12.5 & \\
\hline \multirow{5}{*}{$\begin{array}{l}\text { Associated Health } \\
\text { Problems }\end{array}$} & Gastrointestinal problems & 31 & 12.1 & 12 & 15 & \multirow{5}{*}{$\begin{array}{l}\chi^{2}=5.75 \\
p \text {-value }=.22\end{array}$} \\
\hline & Nervous system problems & 28 & 10.9 & 10 & 12.5 & \\
\hline & Renal disease & 26 & 10.2 & 12 & 15 & \\
\hline & Respiratory disease & 136 & 53.1 & 42 & 52.5 & \\
\hline & Liver problems & 35 & 13.7 & 4 & 5 & \\
\hline \multirow{2}{*}{ Smoking } & Yes & 148 & 57.8 & 51 & 63.7 & \multirow{2}{*}{$\begin{array}{l}\chi^{2}=0.89 \\
p \text {-value }=0.35\end{array}$} \\
\hline & No & 108 & 42.2 & 29 & 36.3 & \\
\hline \multirow{2}{*}{$\begin{array}{l}\text { Using self-care } \\
\text { references }\end{array}$} & Yes & 17 & 6.6 & 7 & 8.7 & \multirow{2}{*}{$\begin{array}{l}\chi^{2}=0.41 \\
p \text {-value }=.52\end{array}$} \\
\hline & No & 239 & 93.4 & 73 & 91.3 & \\
\hline
\end{tabular}

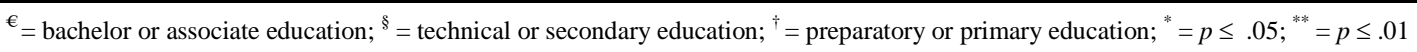

Regarding self-care confidence, as observed in Table 4, all responses in the survey group resulted in means of less than 2.00 which represents a total score of less than $50 \%$ indicating inadequate self-care confidence. This was particularly evident in items 1 and 6 regarding "Confident in being free from HF symptoms" and "Evaluate how well a remedy works" that have means below 1.00. Generally, the total means $=1.4$ for all self-care confidence items which represent inadequate self-care confidence among the survey group in general.

According to the results that presented in Table 5 regarding the perceived QOL among the survey group, all of their responses had means between 3 to 5 which refered to that $\mathrm{CHF}$ patients perceived worse impact of CHF on their QOL. Their total scores were varied from $70 \%$ to $100 \%$, which denoted negative perceptions of the effect of CHF on Egyptian daily life activities and consequently their QOL. The total mean score for all scale items was 4.22 which indicated the worse view of the survey group as regards QOL with CHF. The highest means $(4.78,4.77,4.83)$ were in items $4,10 \& 13$, "Working around the house or yard is difficult", "Sexual activities are difficult", and "Getting tired, fatigued, or having low energy". On the other hand, the lowest means (3.11, 3.28) were in items $17 \& 19$, "Feeling of a burden on family or friends", "Leading cause of worry". In general, the total means $=4.21$ for all QOL items which represented negative perceptions in QOL among the survey group. 
Table 2. Self-care maintenance with CHF as perceived by the survey group and as presented by the mean and standard deviation

\begin{tabular}{lll}
\hline \multirow{2}{*}{ Perceived self-care maintenance with congestive heart failure } & \multicolumn{2}{l}{ Survey group (N = 256) } \\
\cline { 2 - 3 } & Mean & SD \\
\hline Weigh daily & 1.13 & 0.53 \\
Check ankles for swelling & 2.22 & 0.47 \\
Try to avoid getting sick (flu shot, avoid ill people) & 1.28 & 0.44 \\
Do some physical activity & 1.00 & 0.65 \\
Keep doctor or nurse appointments & 2.09 & 0.87 \\
Eat a low sodium diet & 1.67 & 0.67 \\
Exercise for 30 minutes & 1.39 & 0.94 \\
Remember to take medicines & 1.73 & 0.88 \\
Ask for low-salt items when eating out or visiting others & 1.27 & 0.53 \\
Use a system (pill-box, reminder) to help in remembering medicines & 1.53 & 0.74 \\
Total & 1.5 & 0.67 \\
\hline
\end{tabular}

Table 3. Self-care management with CHF as perceived by the survey group and as presented by the mean and standard deviation

\begin{tabular}{lll}
\hline Perceived self-care management with congestive heart failure & Survey group (N = 256) & \% \\
\cline { 2 - 3 } $\begin{array}{l}\text { Trouble breathing or ankle swelling in the past month } \\
\text { Yes }\end{array}$ & No. & 91.4 \\
No & 234 & 8.6 \\
\hline & Survey group (N = 234) \\
Symptom recognition & & 0.23 \\
Symptoms recognized (specifically dyspnea and leg swelling) & 1.22 & 0.23 \\
Treatment implementation & & 0.31 \\
Reduce salt in diet & 1.16 & 0.57 \\
Reduce fluid intake & 1.44 & 0.43 \\
Take an extra water pill & 1.63 & 0.38 \\
Call doctor or nurse for guidance & 1.55 & 0.33 \\
Treatment evaluation & & 0.77 \\
Assurance that the remedy helped & 1.3 & \\
\hline Total & & \\
\hline
\end{tabular}

Table 4. Self-care confidence with CHF as perceived by the survey group and as presented by the mean and standard deviation

\begin{tabular}{lll}
\hline \multirow{2}{*}{ Perceived self-care confidence with congestive heart failure } & \multicolumn{2}{l}{ Survey group (N = 256) } \\
\cline { 2 - 3 } & Mean & SD \\
\hline Confident in being free from HF symptoms & 0.84 & 0.48 \\
Follow the treatment advice given & 1.22 & 0.35 \\
Evaluate the importance of symptoms & 1.64 & 0.58 \\
Recognize changes in health if they occur & 1.63 & 0.43 \\
Do something that will relieve symptoms & 1.83 & 0.55 \\
Evaluate how well a remedy works & 0.96 & 0.71 \\
Total & 1.4 & 0.51 \\
\hline
\end{tabular}

\subsection{Results for experimental group}

Table 6 shows self-care maintenance with CHF as perceived by the experimental group before and after using the devel-

Published by Sciedu Press oped tool in the $1^{\text {st }}, 2^{\text {nd }}$, and $3^{\text {rd }}$ assessments. It is noticed that all 10 items of self-care maintenance have a mean less than 2.00 in the first assessment, except in "Keep doctor or 
nurse appointments" and "Ask for low salt items when eating out or visiting others". These got a mean of more than 2.00. While in the second assessment after use of the developed educational tool, the experimental group responses resulted in means more than 2.00 for most of the self-maintenance scale items with a score less than $70 \%$ which also signified self-care maintenance inadequacy. In items, 1, 2 and 7, "Weigh yourself daily", "Check ankles for swelling" and "Exercise for 30 minutes", the means were still below 2.00 in the second assessment. While in the third assessment, after four weeks of using the developed educational tool, nearly all the experimental group reported means of more than 2.00 with $50 \%$ to $60 \%$ scores that still indicated inadequate self-care maintenance. But in items 3 and 6, "Try to avoid getting sick" and "Eat a low sodium diet", improvement was observed and the perceived responses of the experimental group had means of more than 3 denoting adequate self-care maintenance and above a $70 \%$ score. In general, means in the self-maintenance scale show some improvement in the $2^{\text {nd }}$ and $3^{r d}$ assessments which indicated positive progress in the experimental group perceptions after using the developed educational tool. Almost all item means were below 3 in the $2^{\text {nd }}$ and $3^{r d}$ assessments, but the improvement in perceptions was detected and the total means denoted this improvement. It was observed that there was a strong statistically significant difference between the $1^{\text {st }}, 2^{\text {nd }}$ and $3^{\text {rd }}$ assessments for all scale items as investigated by one way ANOVA $F$-test and $p=.000$.

Table 5. Effects of CHF on the QOL as perceived by the survey group and as presented by mean and standard deviation

\begin{tabular}{|c|c|c|}
\hline \multirow{2}{*}{ Perceived effects of congestive heart failure on quality of life } & \multicolumn{2}{|c|}{ Survey group $(\mathrm{N}=256)$} \\
\hline & Mean & $S D$ \\
\hline Swelling in ankles or legs & 4.34 & 1.82 \\
\hline Sitting or lying down to rest during the day & 4.55 & 0.97 \\
\hline Walking or climbing stairs are difficult & 4.46 & 0.95 \\
\hline Working around the house or yard is difficult & 4.78 & 1.09 \\
\hline Going places away from home is difficult & 3.68 & 1.4 \\
\hline Sleeping well at night is difficult & 4.68 & 0.83 \\
\hline Doing things with friends or family is difficult & 3.89 & 0.96 \\
\hline Working to earn a living is difficult & 3.85 & 1.67 \\
\hline Recreational pastimes, sports or hobbies are difficult & 4.47 & 0.84 \\
\hline Sexual activities are difficult & 4.77 & 1.4 \\
\hline Eating less of liked foods & 4.37 & 1.5 \\
\hline Having shortness of breath & 4.39 & 0.93 \\
\hline Getting tired, fatigued, or having low energy & 4.83 & 1.03 \\
\hline Leading cause for staying in a hospital & 4.26 & 0.84 \\
\hline Costing money for medical care & 4.18 & 0.72 \\
\hline Leading cause of side effects from treatments & 4.23 & 0.77 \\
\hline Feeling of being a burden on family or friends & 3.11 & 0.89 \\
\hline Feeling loss of self-control in life & 3.88 & 0.88 \\
\hline Leading cause of worry & 3.28 & 1.01 \\
\hline Leading cause of difficulty in concentration or remembering things & 3.83 & 0.74 \\
\hline Leading cause of feeling depressed & 3.54 & 0.93 \\
\hline Total & 4.21 & 1.4 \\
\hline
\end{tabular}

In Table 7, concerning perceived self-care management, more than two thirds $(76.2 \%, 72.5 \% \& 61.2 \%)$ of the experimental group experienced trouble breathing or ankle swelling before using the developed educational tool in the first assessment (survey assessment). There was no statistically significant difference between the $1^{\text {st }}, 2^{\text {nd }}$ and $3^{\text {rd }}$ assessments among the experimental group regarding the presence of $\mathrm{CHF}$ complaints wherein $\chi^{2}=4.64$ and $p$-value $=.10$. Each segment of the experimental group who had complaints and responded by yes, continued on to complete the self-care management scale items. For the first assessment, all self-care management items that were perceived by the experimental group (who only had trouble breathing or ankle swelling with CHF) had means below 2.00, but after using the developed tool in the second and third assessments, the improvement was noticeable, exceeding 3.00 in half of these items which represented a score of nearly $75 \%$ and denoted self-care management adequacy. This improvement was noted in items 
2, 3 and 6, "Reduce the salt in your diet", "Reduce fluid symptoms. It is apparent that there was a strong statistically intake" and "Assurance that the remedy helped". The total significant difference between the $1^{\text {st }}, 2^{\text {nd }}$, and $3^{\text {rd }}$ assessmeans in the $3^{r d}$ assessment indicated improvement in self- ments for all scale items as measured by one way ANOVA care management after using the developed educational tool $\quad F$-test and $p=.000$.

among the experimental group who were experiencing $\mathrm{CHF}$

Table 6. Perceived self-care maintenance with CHF in the $1^{\text {st }}, 2^{\text {nd }}$, and $3^{\text {rd }}$ assessments, before and after using the developed tool among the experimental group as presented by mean and standard deviation

\begin{tabular}{|c|c|c|c|c|c|c|c|c|}
\hline \multirow{3}{*}{$\begin{array}{l}\text { Perceived self-care maintenance with } \\
\text { congestive heart failure }\end{array}$} & \multicolumn{6}{|c|}{ Experimental group $(\mathrm{N}=\mathbf{8 0})$} & \multirow{3}{*}{ F-Test } & \multirow{3}{*}{$p$-value } \\
\hline & \multicolumn{2}{|c|}{$1^{\text {st }}$ assessment } & \multicolumn{2}{|c|}{$2^{\text {nd }}$ assessment } & \multicolumn{2}{|c|}{$3^{\text {rd }}$ assessment } & & \\
\hline & Mean & $S D$ & Mean & $S D$ & Mean & $S D$ & & \\
\hline Weigh yourself daily & 1.52 & 1.03 & 1.92 & 0.87 & 2.13 & 1.27 & 6.52 & $.002^{* *}$ \\
\hline Check ankles for swelling & 1.44 & 0.67 & 1.78 & 0.65 & 2.44 & 1.24 & 25.76 & $.002^{* *}$ \\
\hline $\begin{array}{l}\text { Try to avoid getting sick (flu shot, avoid } \\
\text { ill people) }\end{array}$ & 1.56 & 0.57 & 2.00 & 1.94 & 3.44 & 0.68 & 50.99 & $.000^{* * * *}$ \\
\hline Do some physical activity & 1.87 & 1.1 & 2.34 & 0.91 & 2.76 & 0.85 & 50.99 & $.000^{* * *}$ \\
\hline Keep doctor or nurse appointments & 2.14 & 0.85 & 2.14 & 0.65 & 2.87 & 1.05 & 18.97 & $.000^{* * *}$ \\
\hline Eat a low sodium diet & 1.94 & 0.56 & 2.77 & 0.78 & 3.89 & 1.31 & 87.12 & $.000^{* * * *}$ \\
\hline Exercise for 30 minutes & 1.78 & 1.08 & 1.98 & 1.54 & 2.26 & 0.65 & 3.52 & $.031^{*}$ \\
\hline Remember to take medicines & 1.95 & 0.76 & 2.22 & 1.23 & 2.74 & 1.43 & 9.36 & $.000^{* * *}$ \\
\hline $\begin{array}{l}\text { Ask for low salt items when eating out or } \\
\text { visiting others }\end{array}$ & 1.44 & 0.67 & 2.75 & 0.88 & 2.93 & 0.87 & 10.68 & $.000^{* * *}$ \\
\hline $\begin{array}{l}\text { Use a system (pill-box, reminder) to help } \\
\text { in remembering medicines }\end{array}$ & 1.93 & 1.22 & 2.18 & 0.95 & 2.72 & 0.86 & 12.499 & $.000^{* * *}$ \\
\hline Total & 1.84 & 0.85 & 2.2 & 1.04 & 2.8 & 1.02 & 19.845 & $.000^{* * * *}$ \\
\hline
\end{tabular}

${ }^{*}=p \leq .05 ;{ }^{* *}=p \leq .01 ;{ }^{* * * *}=p \leq .001$

Table 7. Perceived self-care management with CHF symptoms in the $1^{\text {st }}, 2^{\text {nd }}$, and $3^{\text {rd }}$ assessments, before and after using the developed tool among the experimental group as presented by mean and standard deviation

\begin{tabular}{|c|c|c|c|c|c|c|c|c|}
\hline \multirow{3}{*}{$\begin{array}{l}\text { Perceived self-care management } \\
\text { with congestive heart failure }\end{array}$} & \multicolumn{6}{|c|}{ Experimental group $(\mathrm{N}=\mathbf{8 0})$} & & \\
\hline & \multicolumn{2}{|c|}{$1^{\text {st }}$ assessment } & \multicolumn{2}{|c|}{$2^{\text {nd }}$ assessment } & \multicolumn{2}{|c|}{$3^{\text {rd }}$ assessment } & \multicolumn{2}{|l|}{$\chi^{2}$} \\
\hline & No. & $\%$ & No. & $\%$ & No. & $\%$ & & \\
\hline \multicolumn{9}{|l|}{$\begin{array}{l}\text { Trouble breathing or ankle } \\
\text { swelling in the past month }\end{array}$} \\
\hline Yes & 61 & 76.2 & 58 & 72.5 & 49 & 61.2 & \multicolumn{2}{|l|}{$\chi^{2}=4.64$} \\
\hline \multirow[t]{3}{*}{ No } & 19 & 23.8 & 22 & 27.5 & 31 & 38.8 & $p$-value & \\
\hline & \multicolumn{2}{|c|}{$\begin{array}{l}\text { Experimental group } \\
\qquad(\mathrm{N}=61)\end{array}$} & \multicolumn{2}{|c|}{$\begin{array}{c}\text { Experimental group } \\
(\mathrm{N}=58)\end{array}$} & \multicolumn{2}{|c|}{$\begin{array}{c}\text { Experimental group } \\
(\mathrm{N}=49)\end{array}$} & F-Test & $p$-value \\
\hline & Mean & $S D$ & Mean & $S D$ & Mean & $S D$ & & \\
\hline \multicolumn{9}{|l|}{ Symptom recognition } \\
\hline $\begin{array}{l}\text { How quickly were heart failure } \\
\text { symptoms recognized (specifically } \\
\text { dyspnea and leg swelling)? }\end{array}$ & 1.76 & 1.08 & 2.17 & 0.79 & 2.68 & 0.87 & 13.373 & $.000^{* * *}$ \\
\hline \multicolumn{9}{|l|}{ Treatment implementation } \\
\hline Reduce the salt in your diet & 1.45 & 0.65 & 2.75 & 0.45 & 3.12 & 0.64 & 127.683 & $.000^{* * *}$ \\
\hline Reduce fluid intake & 1.74 & 0.58 & 2.47 & 0.76 & 3.34 & 1.06 & 53.623 & $.000^{* * *}$ \\
\hline Take an extra water pill & 1.98 & 1.52 & 2.73 & 1.04 & 2.94 & 0.34 & 11.620 & $.000^{* * *}$ \\
\hline Call doctor or nurse for guidance & 1.11 & 0.75 & 1.89 & 0.89 & 2.76 & 0.56 & 65.028 & $.000^{* * *}$ \\
\hline \multicolumn{9}{|l|}{ Treatment evaluation } \\
\hline Assurance that the remedy helped & 1.24 & 0.56 & 2.86 & 0.89 & 3.26 & 1.09 & 89.031 & $.000^{* * *}$ \\
\hline Total & 1.5 & 0.85 & 2.47 & 0.80 & 3.01 & 0.76 & 50.100 & $.000^{* * *}$ \\
\hline
\end{tabular}


Table 8. Perceived self-care confidence with CHF symptoms in the $1^{\text {st }}, 2^{\text {nd }}$, and $3^{\text {rd }}$ assessments, before and after using the developed tool among the experimental group as presented by mean and standard deviation

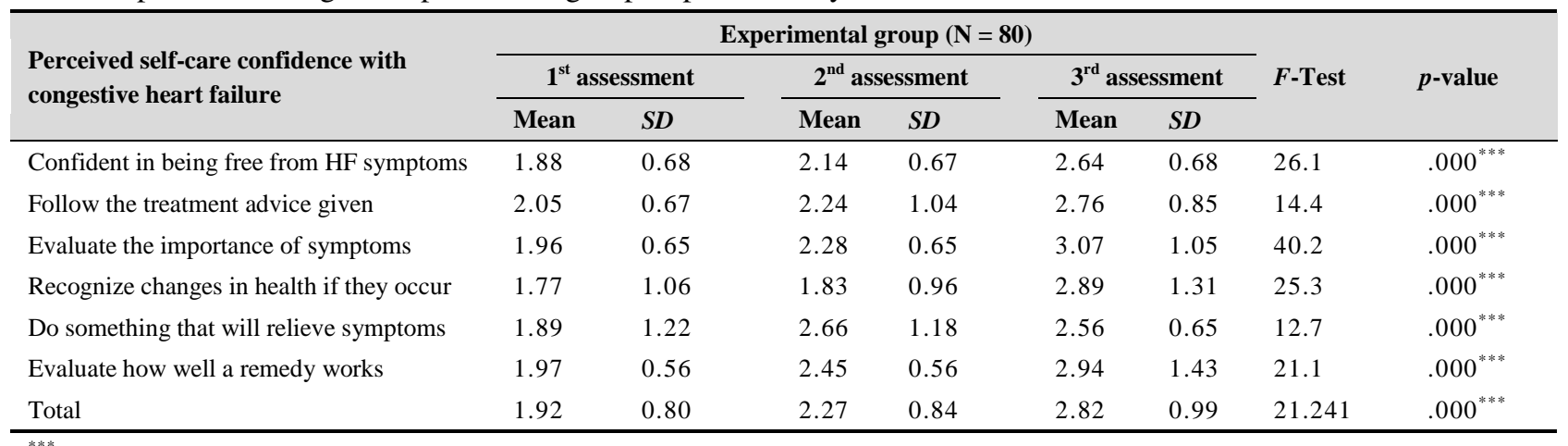

${ }^{* * *}=p \leq .001$

About Table 8, with reference to self-care confidence, it is obvious that the experimental group had inadequate selfcare confidence in the first assessment (survey phase) that reflected on the means of their responses of less than 2.00 and represented $\leq 50 \%$ scores, except in item 18 . These means increased in the 2 nd assessment to between 2.14 to 2.66 that denoted as well $\leq 70 \%$ scores and also inadequate self-care confidence. But in the third assessment and after using the developed educational tool for four weeks, response means increased between 2.56 to 3.07, which approximately indicated adequate self-care confidence with scores $\geq 70 \%$, particularly in items 3,4 , and 6 that had means of above 2.8 . However, in the other items, the experimental group still had inadequate self-care confidence. This indicates that the participants in the experimental group perceived better self-care confidence after using the developed tool. The improvement is very minimal but observable, especially in the total means that shows positive progress. It is obvious that there was a strong statistically significant difference between the $1^{s t}$, $2^{\text {nd }}$, and $3^{\text {rd }}$ assessments for all scale items as computed by one way ANOVA $F$-test and $p=.000$.

Table 9 shows the effects of CHF on the QOL among the experimental group before and after using the developed tool. In the first assessment it is clear that the experimental group had a high burden of disease symptoms on their QOL for all scale items wherein the response means were between 3.11 to 4.63 representing $60 \%$ to $100 \%$ scores and poor perception about QOL. In the second assessment these means decreased to be between 2.52 to 3.88 , except in item 15 (mean $=4.12$ ), which represented as well a poor QOL, but with more positive progress than the first assessment. It is clear that in third assessment the QOL among the experimental group improved, as evidenced by the response means of between 1.16 to 2.22. All items had a mean below 2.5 which indicated positive perceptions regarding QOL. Therefore, the effects of CHF on the QOL among the experimental group before and after using the developed educational tool in the $1^{s t}, 2^{\text {nd }}$, and $3^{\text {rd }}$ assessments are decreased and the perceptions toward QOL is clearly improved. It is obvious if comparing between the total means in the $1^{\text {st }}, 2^{\text {nd }}$, and $3^{r d}$ assessments, which represent $<50 \%$ and better QOL among the experimental group. It is understandable that there was a strong statistically significant difference between the $1 \mathrm{st}$, 2nd, and 3rd assessments for all scale items as calculated by ANOVA $F$-test and $p=.000$.

In Table 10, pertaining to the feedback from CHF patients about use of the developed educational self- care management tool, the experimental group has a positive perception globally for the whole scales point in Tool II in which they got mean values of more than 3.00, indicative of positive feedback. The most apparent items that gained a mean of more than 4 were related to easy use $=4.12$, clarity and understanding $=4.88$, achieving desired expectations $=4.19$ and applicability aspects $=4.23$. Item No. 4 occupied the $1^{\text {st }}$ rank with a mean of 4.88. Concerning the perceived weaknesses of the developed tool, about half (41.3\%) of the experimental subjects perceived that the tool was crowded and needed to be summarized. However, regarding the major strengths, more than half $(51.25 \%)$ of them agreed on the clarity of the tool. As well, $30 \%$ of them recommended decreasing the details and $20 \%$ suggested using more pictures and graphics in the tool.

\section{Discussion}

Most important health goals are attained by doing healthy actions consistently over time. Self-care and self-care management have an established role in health care based practice, and is a target for the expectations of both health-care organizations and patients, particularly with long-term conditions. ${ }^{[23,24]} \mathrm{CHF}$ is a common, costly, disabling, and fatal medical condition faced by a lot of health care professionals which entails multipart management regimens over a 
life-long period. Consequently, self-care management is successful treatment. ${ }^{[3,24,25]}$ an essential part to be learned by this group of patients for

Table 9. Effect of CHF on QOL as perceived by the experimental group in the $1^{s t}, 2^{\text {nd }}$, and $3^{\text {rd }}$ assessments, before and after use of the developed tool as presented by mean and standard deviation

\begin{tabular}{|c|c|c|c|c|c|c|c|c|}
\hline \multirow{3}{*}{$\begin{array}{l}\text { Perceived effects of congestive heart failure on } \\
\text { the quality of life }\end{array}$} & \multicolumn{6}{|c|}{ Experimental group $(\mathrm{N}=\mathbf{8 0})$} & \multirow{3}{*}{ F-Test } & \multirow{3}{*}{$p$-value } \\
\hline & \multicolumn{2}{|c|}{$1^{\text {st }}$ assessment } & \multicolumn{2}{|c|}{$2^{\text {nd }}$ assessment } & \multicolumn{2}{|c|}{$3^{\text {rd }}$ assessment } & & \\
\hline & Mean & $S D$ & Mean & $S D$ & Mean & $S D$ & & \\
\hline Swelling in ankles or legs & 4.11 & 0.82 & 3.56 & 0.76 & 1.26 & 0.75 & 302.676 & $.000^{* * *}$ \\
\hline Sitting or lying down to rest during the day & 3.77 & 0.91 & 3.22 & 0.83 & 2.22 & 0.83 & 67.183 & $.000^{* * *}$ \\
\hline Walking or climbing stairs are difficult & 4.55 & 1.85 & 2.95 & 0.77 & 2.05 & 0.93 & 78.848 & $.000^{* * *}$ \\
\hline Working around the house or yard is difficult & 4.18 & 0.79 & 3.55 & 0.92 & 2.00 & 1.7 & 69.275 & $.000^{* * *}$ \\
\hline Going places away from home is difficult & 3.68 & 1.4 & 3.88 & 1.03 & 1.54 & 0.79 & 110.784 & $.000^{* * *}$ \\
\hline Sleeping well at night is difficult & 3.88 & 0.73 & 3.12 & 0.92 & 2.04 & 1.4 & 61.445 & $.000^{* * *}$ \\
\hline Doing things with friends or family is difficult & 3.49 & 0.76 & 2.54 & 1.03 & 1.16 & 0.73 & 151.714 & $.000^{* * *}$ \\
\hline Working to earn a living is difficult & 3.05 & 0.83 & 2.63 & 0.94 & 2.18 & 1.85 & 9.095 & $.000^{* * *}$ \\
\hline Recreational pastimes, sports or hobbies are difficult & 4.48 & 0.93 & 3.77 & 0.91 & 1.49 & 0.92 & 230.647 & $.000^{* * *}$ \\
\hline Sexual activities are difficult & 4.87 & 1.7 & 3.54 & 1.85 & 1.55 & 1.03 & 90.875 & $.000^{* * *}$ \\
\hline Eating less of the liked foods & 4.44 & 1.85 & 3.13 & 0.79 & 2.13 & 0.83 & 68.016 & $.000^{* * *}$ \\
\hline Shortness of breath & 4.39 & 0.92 & 3.36 & 0.82 & 1.35 & 0.93 & 240.678 & $.000^{* * *}$ \\
\hline Getting tired, fatigued, or having low energy & 4.63 & 1.03 & 3.04 & 0.91 & 2.13 & 1.7 & 80.403 & $.000^{* * *}$ \\
\hline Leading cause for staying in a hospital & 3.36 & 0.94 & 2.52 & 1.85 & 1.68 & 1.03 & 31.553 & $.000^{* * *}$ \\
\hline Costing money for medical care & 4.38 & 0.92 & 4.12 & 1.03 & 2.18 & 1.4 & 89.687 & $.000^{* * *}$ \\
\hline Leading cause of side effects from treatments & 3.23 & 0.87 & 3.12 & 0.94 & 1.54 & 0.73 & 98.732 & $.000^{* * *}$ \\
\hline Feeling a burden on family or friends & 3.11 & 0.84 & 3.64 & 0.92 & 2.06 & 0.76 & 72.874 & $.000^{* * *}$ \\
\hline Feeling a loss of self control in life & 3.88 & 0.76 & 2.85 & 0.79 & 1.48 & 1.03 & 153.766 & $.000^{* * *}$ \\
\hline Leading cause of worry & 3.65 & 1.81 & 2.55 & 1.4 & 1.65 & 0.92 & 39.589 & $.000^{* * *}$ \\
\hline $\begin{array}{l}\text { Leading cause of difficulty concentrating or } \\
\text { remembering things }\end{array}$ & 3.33 & 0.94 & 2.91 & 0.73 & 1.23 & 1.03 & 119.622 & $.000^{* * *}$ \\
\hline Leading cause of feeling depressed & 3.37 & 0.87 & 3.17 & 0.84 & 1.53 & 0.94 & 104.262 & $.000^{* * *}$ \\
\hline Total & 3.9 & 1.07 & 3.2 & 0.99 & 1.8 & 1.05 & 85.019 & $.000^{* * *}$ \\
\hline
\end{tabular}

Patient health education is proposed to promote self-care management of patients with CHF. There are specific educational techniques which help patients in attaining their wishes through well planned self- care management educational programs. The most apparent approaches used are the instructional tools for $\mathrm{CHF}$ patients who are receiving inpatient medical treatment. Nurses are the key ones to provide health education and prepare such tools. The nurse as a health educator should be aware of updating knowledge as well as the educational, communicational, and social processes of health education. It is very important to emphasize that health education requires a nurse specialist with broad knowledge and skills related to educational activities and the ability to integrate them with different diseases, especially chronic ones. ${ }^{[26,27]}$

Self-instructional materials are the backbone of self-care management health education for any chronic condition. The nurse as a health educator must prepare, plan, develop, implement and evaluate these materials as a basic role in nursing activities. Because patients live healthier when they are continuously informed, patient educational materials, including visual aids, charts, pamphlets, flyers, posters and models, are vital tools as literary self resources. Patient teaching tools are designed specifically to help the nurse educator communicate with patients and offer them the best possible health-care management.

In the present study in the survey phase, there were serious negative perceptions about self-care management in general. Regarding the three elements of self-care management and in particular for self- care maintenance, it was noticed that the majority of the survey group perceptions had means of less than 3 which represented inadequate self-care maintenance achievement. This result reflects the bad effect of low literacy about assessing the disease symptoms in Egypt, which is 
completely undesirable in chronic diseases. Congruent with this view, self-care maintenance is the most vital element of self-care management in general, as discussed by Riegel B et al., in 2009, who reported that self-care maintenance entails symptom monitoring and treatment obedience which are the most important aspects of patient-care management. The careful attention to symptom observation is essential for rec- ognizing and interpreting symptoms. As well, Tung H. et al., in 2013, reported that treatment adherence and observing disease symptoms is the main element of self-care management which is the self-care maintenance. This self-care maintenance included healthy behaviors such as taking medications, exercising, and following a salt restricted diet. ${ }^{[2,4,27]}$

Table 10. Feedback after using the developed self-care management tool as perceived by the experimental group

\begin{tabular}{|c|c|c|}
\hline \multirow[t]{2}{*}{ Patient feedback after using the developed tool } & \multicolumn{2}{|c|}{$\begin{array}{l}\text { Experimental group }(\mathrm{N}=80) \\
3^{\text {rd }} \text { Assessment }\end{array}$} \\
\hline & Mean & $S D$ \\
\hline How far is the content of the tool suitable? & 3.33 & 1.03 \\
\hline How far is the content of the tool relevant to literacy level? & 3.78 & 0.83 \\
\hline How easy is the tool? & 4.12 & 0.93 \\
\hline How clear and understandable is the tool? & 4.88 & 1.7 \\
\hline How accurate is the data in the tool? & 3.15 & 1.03 \\
\hline How far does the tool achieve your expectation? & 4.19 & 0.91 \\
\hline How good are the organizational aspects of the tool? & 3.57 & 1.03 \\
\hline How good are the attractiveness and interesting aspects of the tool? & 3.00 & 0.92 \\
\hline How good are the applicability aspects in the tool instructions? & 4.23 & 1.03 \\
\hline How far does the tool's instruction satisfy individual differences? & 3.45 & 0.94 \\
\hline How appropriate is the content, vocabulary, sentence structure, and concepts? & 3.87 & 1.05 \\
\hline How far is the tool a useful educational resource? & 4.25 & 1.34 \\
\hline \multirow[t]{2}{*}{ Total } & 3.81 & 1.23 \\
\hline & No. & $\%$ \\
\hline \multicolumn{3}{|l|}{ Weak points of the tool: } \\
\hline Crowded & 33 & 41.3 \\
\hline Poor organization & 24 & 30 \\
\hline Difficult to follow & 18 & 22.5 \\
\hline Need training & 9 & 11.25 \\
\hline None & 16 & 20 \\
\hline \multicolumn{3}{|l|}{ Strong points of the tool: } \\
\hline Clear & 41 & 51.25 \\
\hline Useful & 19 & 23.75 \\
\hline Self reference & 10 & 12.5 \\
\hline None & 10 & 12.5 \\
\hline \multicolumn{3}{|l|}{ Suggestions to improve the tool: } \\
\hline Decrease details of the tool & 24 & 30 \\
\hline Use pictures and graphics & 16 & 20 \\
\hline Clarify how to write nursing diagnosis related to knowledge & 7 & 8.75 \\
\hline Develop a model for each specialty & 10 & 12.5 \\
\hline Develop a guide for health teaching of each health problem & 9 & 11.25 \\
\hline Develop a model for each phase of patient health education & 9 & 11.25 \\
\hline None & 5 & 6.25 \\
\hline
\end{tabular}

Concerning the second element of the self-care management scale, which is self-care management, almost the entire survey group had trouble breathing or ankle swelling within the previous month and the majority of their perceptions had means of less than 2.00 for symptom recognition, treatment implementation and treatment evaluation. This denoted inadequate self-care management among Egyptian patients with CHF. In these chronic cases, the key to decision making is symptom recognition and care behaviors. When recognition fails, as it does frequently with CHF patients in Egypt, poor 
management will result. Therefore, in general, self-care management is a crucial component of self-care which reflects self-dependence in interpretation, practicing of self-care behaviors and using and appraising the prescribed treatment in particular for patients with chronic illness. This view is supported by Meng K. in 2013, who stressed that during the CHF inpatient period, predominantly comprehensive pharmaceutical treatment and its education is offered to patients with myocardial infarction. For those patients receiving surgery or catheter-based interventions, education regarding home-care management is vital. Subsequently, all therapeutic regimens need careful awareness, interpretation and positive attitudes from patients. ${ }^{[25,28]}$ This is goes in line with Rankin S., in 2002, who clarified that patient literacy, inner motivation and a positive attitude regarding self-care management of their own health and illness care is considered a foundation of health-care management. Nurses should focus on helping them to acquire all skills, attitudes or knowledge needed to manage health complaints accurately. ${ }^{[29]}$ Supporting this point, Barlow J, et al., in 2002, discussed that self-care management is the individual's ability to manage symptoms, treatment, physical and psychosocial consequences and lifestyle changes inherent in living with a chronic condition, to affect the cognitive, behavioral and emotional responses necessary to maintain a satisfactory QOL. CHF patients should participate in the dynamic and continuous process of self-regulation by integrating health literacy about the disease including definition, etiology, symptoms and signs, pharmacological treatment, risk factor modification, diet and exercise recommendations, sexual activity limitations, immunizations, sleep and breathing disorders, treatment adherence, and finally with psychosocial aspects and prognosis, each associated with certain skills or self-care management behaviors. ${ }^{[25,30]}$

An observed survey group perception which gained a low mean in self-care management items was "assurance that the remedy helped". Although remedies are popular self-care approaches in Egypt, CHF patients still have low awareness and inadequate perception as regards to these valuable health management components. This result is congruent with Fathi A, in 2015, who conducted a study in Egypt and found that patient literacy about herbs as a self-care management approach was very limited. Nurses have a great and nuclear function to use suitable teaching interventions that help in addressing patient needs, particularly among patients with complaints in a vital body organ. ${ }^{[31]}$ Contradicting this view of patients, Brent A. and Bauer MD, in 2005, mentioned that herbal therapy is a common perceived approach used by patients with chronic disease due to multiple factors such as inexpensiveness of its pharmaceutical preparations, having few side effects, lacking in stomach irritation if swallowed and often not dangerous. As well, herbals are often perceived as being "naturals" and therefore are considered a safe product for healthy and diseased people. ${ }^{[31,32]}$ As a comment for both opposing views, patient awareness of herbs and their potential benefits and risks will enable health professionals to provide a balanced and objective view regarding them. Nurses are a source of encouraging clients to have appropriate information to make an informed choice regarding complementary and non complementary therapies.

In the current study, the result revealed that survey subjects have inadequate self-care confidence, the third part of selfcare management, which was reflected through their response means. Self-care confidence is a valuable parameter of selfcare management that represents the ability of the patient to be independent as long as possible and the inner beliefs of capabilities and power to achieve own self care. Therefore, based on this result, Egyptian patients with CHF have inadequate self-care confidence which needs critical attention. Similarly, Meng K, et al., in 2013, emphasized that the majority of patients with chronic conditions lacked self-care efficacy and self-care confidence in monitoring and managing illness complaints. ${ }^{[25]}$ Contradictory to this, Riegel B, et al., in 2009, reported that inner motivation and appreciation of one's own abilities to monitor, perform and evaluate self care, plays an important role in CHF management. On the other hand, patients must be alert to use astuteness, thought, and perception in response to directions from an external source for strengthening self efficacy or self confidence to enhance their ability to accomplish self-care goals. ${ }^{[2,25,30]}$ Further, Vellone E. et al., in 2013, discussed that self- care confidence requires intellectual skills that directly force the process of therapeutic decision making and performance of the patient's self-care. ${ }^{[33]}$ It is believed that self-care confidence has a moderating effect on self-care at different outcomes such as in treatment adherence and the implementation of multidisciplinary programs with home visits and telephone follow-up so that patients recognize and properly handle their symptoms. ${ }^{[34,35]}$ However, many Egyptian patients with $\mathrm{CHF}$ didn't perceive the importance of this as a predictor of successful self care. These results provide a great question for health care professionals; "How can the perceptions of people regarding self-care confidence be improved?"

Pertaining to the QOL, the majority of the survey group perceived negative perceptions as regards their QOL when accompanied with a heart condition. This refers to the great effect of CHF on Egyptian patient daily life activities. These are expected results because the survey group has inadequate self-care maintenance, management and confidence. Therefore, they have an inadequate QOL and all efforts must be 
taken to improve it among this group of patients. Dissimilarly to this result, Conceição A. et al., in 2015, stressed that a persistent illness experience forces patients to combine practices and health education into self care, with the intention of maintaining the greatest well being and QOL as possible. Self-care promotion is necessary in chronic disease wherein patients are obligated to link it with daily living activities and skills to improve their QOL. ${ }^{[36,37]}$ Almost all the survey group viewed that "Working around the house or yard are difficult", "Sexual activities are difficult", and "Getting tired, fatigued, or have low energy" were the most prevalent activities that were affected by the chronic disease. This indicates that the major complaints of these patients belonged to physical activities. Coelho R. et al., in 2005, likewise mentioned that CHF is a major health problem with increasing incidence and poor prognosis. Thus patients have to restrict physical activity and cope with many complaints in several areas of the QOL. ${ }^{[38]}$ Congruently with patient responses, Bosworth HB. et al., in 2004, illustrated that CHF decreases well being abilities and physical performance and deteriorates the QOL primarily on physical symptoms rather than capturing the full range of psychosocial concerns. ${ }^{[39]}$ Therefore, expectedly, the survey group reported the worse impact of CHF was apparent on physical symptoms which is an important dimension of QOL. Alterations in the lives of the patients with CHF were not always understood as deficiencies, but rather an adaptation approach.

On the other hand, health professionals must recognize all aspects of concerns affecting the QOL for patients with CHF Coelho R. et al., in 2005, discussed that the goal of the measurement of the QOL is to have objective evaluations of how and how much the disease influences patients' lives and how patients cope with it. These evaluations may be helpful as a baseline, outcome measures and an assessing framework to determine the change on patient QOL. ${ }^{[38]}$ Additionally, nurses are acquainted with behaviors that need to be modified or added for better disease control and consequently, a better QOL for CHF people. ${ }^{[36]}$ QOL is a main goal in the perspective of preventive and palliative therapeutic cardiology for all clinicians. Better QOL is the subtle hope among nurses and a valuable concern in health education among patients with chronic conditions.

The current study confirms that use of a self-care management tool as a self-instructional aide generated real and noticeable effects on perceptions of CHF patients regarding self-care management, particularly for its benefits on patient knowledge about health care activities which supports the first hypothesis. It is clear that there was a strong statistically significant difference between the $1^{\text {st }}, 2^{\text {nd }}$, and $3^{\text {rd }}$ assessments for all scale items $p=.000$. After using the self- care management instructional tool, the experimental group demonstrated apparent improvements in their perceptions for all self-care management parameters and QOL, opposite to the perceptions among the survey group, especially in the $3^{\text {rd }}$ assessment.

It was observed that the perceptions of patients with CHF among the experimental group as regards self-care maintenance were improved before and after using the developed educational tool in the $2^{\text {nd }}$, and $3^{\text {rd }}$ assessments. This proves that the self-care management tool may be effective as a selflearning reference among Egyptian CHF patients. Patient education is a cornerstone of patient health management. This result is in line with Aleda MH. et al., in 2009, who concluded that there is a strong association between health literacy and self-care maintenance in CHF. With continuous self-learning follow up, patients are executing more self-care monitoring and control, which leads to improved prognosis and outcomes in heart failure. Patients with elevated health literacy move towards having greater self-care maintenance that enforces performing of self care. Vice versa, patients with lower health literacy have low self-care maintenance. Health education tools act as a reminder for self-care maintenance. Moreover, it is a basic nursing principle and obligation to encourage each individual, through patient and family education, to carry responsibility for disease management, prevention and health promotion. Nurses as health educators teach, modify, correct, stress, persuade and promote healthy behaviors as well as appraise risk factors and facilitate discharge planning through the effective planning, developing, implementing and evaluating of instructional aides. ${ }^{[18,26,40]}$ Harmonious to this finding, Siabani S. et al., in 2015, concluded that health education in home-based visits and use of self learning tools by CHF patients improved self-care maintenance and self-care management as a whole. However, many of the health education interventions targeting self-care maintenance improvement require substantial financial resources and advanced technology that cannot be provided easily, especially in less-developed and low income countries. ${ }^{[41]}$ Therefore, in Egypt, the development of health education tools requires evident consideration from the government and Ministry of Health for developing these materials, particularly with chronic cases. As well as creating, establishing and applying innovative educational interventions among health professionals such as nurses. In Egypt, although patient education is a necessary element of a total care plan and despite multiple improvement efforts, it remains inconsistent and minimally effective.

In relation to the second element of self-care which is selfcare management, there is an observed improvement in the 
experimental group perceptions before and after use of the developed tool in the $2^{\text {nd }}$ and $3^{\text {rd }}$ assessments. This result is expected because of the effective use of health teaching, follow up and the evaluation process through applying the developed tool as a self-learning reference. It is a valuable methodology to change individual behaviors and attitudes or perceptions. Effective health education provides a good chance to affect positively patient attitudes which of course will be reflected on self-care performance. Correspondingly, health education and teaching tools and materials with $\mathrm{CHF}$ patients offers a good chance for acquiring basic knowledge regarding self-care and skills to achieve suitable self-care management. Therefore, use of educational materials to help patients change unhealthy perceptions to healthy ones, is a useful approach among patients with chronic conditions. Consequently, by use of this approach, patients can carry the responsibility for their health concern. ${ }^{[26,40,41]}$

Concerning the third element of self-care management which is self-care confidence, almost all the experimental group shows an observed improvement before and after using the developed tool in the $2^{\text {nd }}$ and $3^{\text {rd }}$ assessments. Congruent with this finding, Siabani S. et al., in 2015, discussed that self-care confidence was greater among study groups who receive health education and interact using the educational materials. Additionally, patients with proper health teaching reflected satisfactory self-care confidence with an inner ability to decrease the need for hospital admissions through early recognition of $\mathrm{CHF}$ symptoms. Taking appropriate decisions for managing $\mathrm{CHF}$ symptoms prevents deterioration of the health status too far and is reflected by a well state of self-care confidence. ${ }^{[36,41]}$

On the other hand, patients with low literacy and poor selfawareness will have limited self-care confidence and consequently, the inability to identify disease features, manage illness complaints or take failing health related decisions. Therefore, health education tool utilization by health staff led to real improvement in self confidence and total self-care management. World-wide accepted methods for prevention and self-care management of chronic illness are the health education messages throughout different guiding materials. Expert health educators with $\mathrm{CHF}$ patients are required to be competent in knowledge and skills of educational materials related to the recognition, diagnosis, caring and referral for patients. ${ }^{[5,17,34]}$

In relation to experimental group perceptions regarding QOL, the effects of CHF on QOL before and after using the developed tool are decreased and the QOL is clearly improved, especially in the 3rd assessment. Without any doubt, the liter- ate patients who are guided continuously, advised, educated and have educational tools for self-leaning will adapt to all disease-related problems whether physical, mental, social or spiritual. Congruent to this result, Babaee G. et al., in 2012, emphasized that the QOL has emerged as an important concept and outcome in health and health-care education. Health care staff has often used health-related QOL to measure the effect of chronic illness in their patients in order to better understand how an illness interferes with a person's day-to-day life. Patient education in all educational activities including guided tools, aspects of therapeutic education, educational intervention and clinical health promotion, can improve knowledge and skills, and consequently patient QOL as a whole. Patient literacy regarding own chronic disease tends to improve QOL. Accordingly, there is a strong relation between health education and good QOL. ${ }^{[42,43]}$

As well, Switek J., in 2002, found that there was a significant increase in the QOL scores for the supportive educational group occurring at the six month time period. ${ }^{[4]}$ Jaarsma T, et al., in 2000, demonstrated similar results in a study conducted with patients with advanced heart failure that received a supportive educational nursing intervention. He found that the control group who received routine nursing care and the experimental group who received supportive education, showed improvement in the QOL dimensions after the baseline measurement, but without any differences between both. However, Hawthorne and Hixon, in 1994, examined the effects of a nurse monitored, symptom management program on hospital readmission rates and QOL in patients with chronic heart failure. They found that QOL did not improve until the patients were stratified by activity levels wherein the higher activity group had a statistically significant increase in QOL scores. ${ }^{[45,46]}$ QOL can be observed and examined on a range of dimensions that is dependent on the degree of patient condition stability and assessment of which external factors are affecting this stability. QOL should be investigated generally in relation to physical, psychological, and social domains of health. It is seen as distinct areas that are influenced by a person's experiences, beliefs, expectations and perceptions. Self-care management is a critical indicator and important factor affecting QOL.

The measurement and evaluation of QOL has become more and more significant in health care practice, research, and social sciences. Development and advances in health care, QOL measurement and determination of affecting factors can assist in treatment decisions and intervention judgment, particularly in a disease such as CHF with its high morbidity and mortality, and growth of new cases. It is apparent that QOL is an important clinical outcome when measuring 
health outcomes after nursing educational interventions.

\section{Conclusion}

Health teaching printed materials regarding self-care management verifies that it is an essential strategy to improve self-care management (including self-maintenance, selfmanagement and self- confidence) and the QOL among patients with $\mathrm{CHF}$, thus strengthening the role of the nurse in the health education paradigm. With implementation of instructional aides among patients with chronic diseases, nurses will re-establish a key role in this aspect. Patient literacy about self-care management is considered a nuclear function and great responsibility of the professional nurse. Therefore, in the light of educational preparation for nurses, enough experiences in developing patient teaching instructional materials in CHF will be an incomparable step for improving our nursing profession.

\section{Recommendations and further studies}

Heart failure is a common, debilitating and costly disease with a poor prognosis that is growing in frequency and prevalence. It is a chronic condition that not only affects patients but also families and communities. Research conducted on the heart failure population in self-care management and
QOL has shown that these patients have inadequate self-care management plus a poor QOL. Collaboration among the cardiology team and other disciplines is encouraged especially in health education. The present study provided a view for further studies such as:

(1) Investigation into the relation between awareness of patients with CHF towards health education and their compliance in this aspect.

(2) Collaboration for relevant research in chronic conditions and electronic health education to test their safety and efficacy for managing disease with internet interactive teaching tools.

(3) Conduction of other research into using other types of teaching strategies for $\mathrm{CHF}$ patients and investigate its effectiveness on other parameters such as patient satisfaction, patient self efficacy and health belief.

(4) Replication of the current study with other clinical instruments and laboratory investigations such as x rays, cardiac enzymes, electrocardiograms and physical examinations.

(5) Studying a larger sample, as well as a longer period of time to confirm the effect of the health education tool on improving self-care management, QOL and the minimization of disease-related health problems.

\section{REFERENCES}

[1] Rector TS. Overview of the Minnesota Living with Heart Failure Questionnaire. 2005. Available from: http://www.mlhfq.org/_d nld/mlhfq_overview.pdf

[2] Riegel B, Lee CS, Dickson VV, et al. An update on the self-care of heart failure index. The Journal of Cardiovascular Nursing. 2009; 24: 485-497. http://dx.doi.org/10.1097/JCN.0b013e3181b $4 \mathrm{baa0}$

[3] Bodenheimer T. Partnering in Self-Management Support: A Toolkit for Clinicians: Helping Patients Manage Their Chronic Conditions. Institute for Healthcare Improvement. 2009; 1-34.

[4] Tung H, Lin C, Chen K, et al. Self-Management Intervention to Improve Self-Care and Quality of Life in Heart Failure Patients Congest Heart Fail. 2013; 19(40): E10-E16.

[5] Lorig KR, Holman HR. Self-management education: history, definition, outcomes, and mechanisms. Ann Behav Med. 2003; 26: 1-7. http://dx.doi.org/10.1207/S15324796ABM2601_01

[6] Stewart S, MacIntyre K, Capewell S, et al. Heart failure and the aging population: an increasing burden in the $21^{\text {st }}$ century. Heart. 2003; 89: 49-53. PMid: 12482791. http://dx.doi.org/10.1136/hea rt.89.1.49

[7] Tai MK. Evidence-based practice of fluid restriction in patients with heart failure. JNR. 2009; 56: 23-29.

[8] World Bank. World Development Report 2000/2001: Attacking poverty. Washington, DC: World Bank. 2000.

[9] Heo S, Moser DK, Riegel B. Testing the psychometric properties of the Minnesota living with HF questionnaire. Nurs Res. 2005; 54:
265-272. PMid: 16027569. http://dx.doi.org/10.1097/000 06199-200507000-00009

[10] Driscoll A, Davidson P, Clark R, et al. Tailoring consumer resources to enhance self-care in chronic heart failure. Australian Critical Care. 2009; 22: 133-140. PMid: 19581110. http://dx.doi.org/10.10 $16 / j$. aucc. 2009.05.003

[11] Horwitz L, Krumholz H, Hunt S, et al. Heart failure self management. Up to date Ministry of Health. 2013.

[12] Smeulders E. Heart failure self-management: balancing between medical and psychosocial needs, Evaluation of a cognitive-behavioral self-management group program. Published doctoral thesis Maastricht University. 2010. Available from: http://pub. maastricht university.nl/b53fb42d-a368-4645-be9e-8ea6e60ef0cf

[13] Riegel B. Foreword: Self-care of heart failure: what is the state of the science? J Cardiovasc Nurs. 2008; 23(3): 187-9. PMid: 18437058. ht tp://dx.doi.org/10.1097/01. JCN .0000305087.12388.10

[14] Jaarsma T, Halfens R, Huijer Abu-Saad H, et al. Effects of education and support on self-care and resource utilization in patients with heart failure. Eur Heart J. 1999; 20(9): 673-82. PMid: 10208788. http://dx.doi.org/10.1053/euhj .1998.1341

[15] Recovery Information, Introduction to Self Management Tools Sussex Partnership NHS Foundation Trust. 2010. Available from: http://www.google.com.sa/url?sa=t\&rct=j\&q=\&esrc= s\&source=web\&cd=1\&ved=0CCMQF jAA\&url=http $\% 3 \mathrm{~A} \% 2 \mathrm{~F} \% 2 \mathrm{Fww}$ w. sussexpartnership.nhs.uk\% $2 \mathrm{Ffile} \% 2 \mathrm{~F} 867 \% 2 \mathrm{Fdownload}$ \%3Ftoken\%3DxY2g9y14\&ei=BdtqVc6P04K9ggSZi4KQCg\&usg=A FQjCNHHs5DZHXaiHYz7swHakwEjBWokmg 
[16] Deegan P. Recovering our sense of value after being labeled. Journal of Psychosocial Nursing, 1993; 31(4): 7-11.

[17] Oueda M. Analytical Review for Models Related to Health Education. Faculty of Nursing. University of Alexandria. 1999; 1-8, 13-35.

[18] Fathi A. Development of Patient Health Education Model to Guide Undergraduate Nursing Students. Unpublished MSN Thesis. Alexandria: University of Alexandria, Faculty of Nursing; 2006. 23-37.

[19] Barrett M. Patient Self Management Tools: An Overview. California Health Care Foundation. 2005; 5-30. PMid: 16219606.

[20] Washburn SC, Hornberger CA. Nurse Educator guidelines for the management of heart failure. The Journal of Continuing Education in Nursing. 2008; 39(6): 263-267. http://dx. doi .org/10. 3928 100220124-20080601-10

[21] Walker C. Effects of the Use of a Heart Failure Diary on Self- Care and Quality of Life. Master's Thesis. UNF Digital Commons. University of North Florida. 2011; 65: 1-55.

[22] Bodenheimer A. Patient Self-Management of Chronic Disease in Primary Care. Journal of the American Medical Association. 2002; 288(19): 2470. http://dx.doi.org/10.1001/jama.288.19.2 469

[23] Riegel B, Carlson B, Moser DK, et al. Psychometric testing of the self-care of heart failure index. Journal of Cardiac Failure. 2004; 10(4): 350-360. http://dx.doi .org/10.1016/j. cardfail . 20 03.12 .001

[24] Hill L, Roberts G, Igbrude W. How can mental health services support self management? The experience of Support Time and Recovery workers in promoting WRAP. Psychiatric Bulletin. 2009.

[25] Meng K, Musekamp G, Seekatz B, et al. Evaluation of a selfmanagement patient education program for patients with chronic heart failure undergoing inpatient cardiac rehabilitation: study protocol of a cluster randomized controlled trial. BMC Cardiovascular Disorders. 2013; 13(9): 60. PMid: 23968340. http://dx.doi.o $\mathrm{rg} / 10.1186 / 1471-2261-13-60$

[26] Abd El Mohsen A. Barriers Encountered by Undergraduate Nursing Students While Providing Health Education for Patients. Unpublished Master Thesis. Faculty of Nursing, University of Alexandria; 2009. 14-35.

[27] While A, Kiek F. Chronic heart failure: promoting quality of life. Br J Community Nurs. 2009; 14: 54-59. PMid: 19223810. http://dx.doi.org/10.12968/bjcn.2009.14.2.38760

[28] Karoff M, Held K, Bjarnason-Wehrens B. Cardiac rehabilitation in Germany. Eur J Cardiovasc Prev Rehabil. 2007; 14: 18-27. PMid: 17301623. http://dx.doi.org/10.1097/HJR.0b013e3 280128bde

[29] Rankin S, Stallings D. Patient Education: Principles and Practice. New York: Lippincott publisher; 2001. 290-400 p.

[30] Barlow J, Wright C, Sheasby J, et al. Self management approaches for people with chronic conditions: a review. Patient Educ Couns. 2002; 48: 177-187. http://dx.doi.org/10.1016/S0738-399 1(02) 00032-0

[31] Fathi A, Tawfik F, Matter A. Oral health education for diabetic patients with gingivitis: Controlled before and after trial. Clinical Nursing Studies. 2015; 3(3): 105-117.
[32] Brent A, Bauer, MD. Herbal Therapy: What a Clinician Needs to Know to Counsel Patients Effectively. Nurse Education Today Journal. 2005; 80(6): 828.

[33] Vellone E, Riegel B, Cocchieri A, et al. Validity and reliability of the caregiver contribution to self-care of heart failure index. J Cardiovasc Nurs. 2013; 28(3): 245-55. PMid: 22760172. http: //dx.doi.org/10.1097/JCN.0b013e318256385e

[34] Dickson VV, Melkus GD, Katz S, et al. Building skill in heart failure self-care among community dwelling older adults: Results of a pilot study. Patient Educ Couns [Internet]. 2014. PMid: 24910422 http://dx.doi.org/10.1016/j.pec.2014.04.018

[35] Agvall B, Alehagen U, Dahlström U. The benefits of using a heart failure management programme in Swedish primary healthcare. Eur J Heart Fail. 2013; 15(2): 228-36. PMid: 23109650 http://dx.doi.org/10.1093/eurjhf/hfs159

[36] Conceição A, Santos M, Santos B, et al. Self-care in heart failure patients. Rev. Latino-Am. Enfermagem. 2015; 23(4): 578-86. http://dx.doi.org/10.1590/0104-1169.0288.2591

[37] Wilkinson A, Whitehead L. Evolution of the concept of self-care and implications for nurses: a literature review. Int J Nurs Stud. 2009; 46(8): 1143-7. PMid: 19200992. http://dx.doi.org/10.1016 /j.ijnurstu.2008.12.011

[38] Coelho R, Ramos S, Prata J, et al. Heart failure and health related quality of life. Clin Pract Epidemiol Ment Health. 2005; 1: 19 http://dx.doi.org/10.1186/1745-0179-1-19

[39] Bosworth HB, Steinhauser KE, Orr M, et al. Congestive heart failure patients' perceptions of quality of life: the integration of physical and psychosocial factors. Aging Ment Health. 2004; 8(1): 83-91. PMid: 14690872. http://dx.doi.org/10.1080/13607860310 001613374

[40] Aleda MH, Chen KS, Kimberly YS, et al. Health Literacy and SelfCare of Patients with Heart Failure. Purdue University. 2009.

[41] Siabani S, Driscoll T, Davidson P M, et al. Efficacy of a home-based educational strategy involving community health volunteers in improving self-care in patients with chronic heart failure in western Iran: A randomized controlled trial. European Journal of Cardiovascular Nursing. 2015; 11: 84. http://dx.doi.org/10.1177/1474515 115585651

[42] Babaee G, Keshavarz M, Shaiegan M. Effect of a Health education program on quality of line in patients undergoing coronary artery bypass surgery. Acta Medica Iranica. 2012; 45(1): 69-75.

[43] Visser A. Chronic diseases, aging and dementia: implications for patient education and counseling. Patient Educ Couns. 2000; 39(2): 293302. http://dx. doi.org/10.1016/S0738-3991 (99) 00002-6

[44] Switek J. The Effect of Supportive Education, as a Tertiary Nursing Intervention, on the Quality of Life of Patients with Heart Failure. Published Master Thesis. Grand Valley State University. 2002.

[45] Jaarsma T, Hal fens R, Tan F, et al. Self-care and quality of life in patients with advanced heart failure: The effect of supportive educational intervention. Heart and Luna. 2000; 29(5): 319-330. PMid: 10986526. http://dx.doi.org/10.1067/mhl.2000.108323

[46] Hawthorne MH, Hixon ME. Functional status, mood disturbance, and quality of life in patients with heart failure. Cardiovascular Nursing. 1994; 9(1): 22-32. 